Article

\title{
Innovative Methodology to Identify Errors in Electric Energy Measurement Systems in Power Utilities
}

\author{
Marco Toledo-Orozco ${ }^{1,2, * \mathbb{0}}$, Carlos Arias-Marin ${ }^{3}$, Carlos Álvarez-Bel ${ }^{1}$, Diego Morales-Jadan ${ }^{4}(\mathbb{D}$, \\ Javier Rodríguez-García ${ }^{1}(1)$ and Eddy Bravo-Padilla ${ }^{2}$ \\ 1 Institute for Energy Engineering, Universitat Politècnica de València, Camino de Vera, 46022 Valencia, Spain; \\ calvarez@die.upv.es (C.Á.-B.); jarodgar@iie.upv.es (J.R.-G.) \\ 2 School of Electrical Engineering, Faculty of Engineering, Universidad de Cuenca, Cuenca 010109, Ecuador; \\ eddy.bravop@ucuenca.edu.ec \\ 3 Electrical Engineering Career, Universidad Politécnica Salesiana, Sede Cuenca 010103, Ecuador; \\ cariasma@est.ups.edu.ec \\ 4 Electrical Engineering Career, Circular Economy Laboratory-CIITT, Universidad Católica de Cuenca, \\ Sede Cuenca 010107, Ecuador; dmoralesj@ucacue.edu.ec \\ * Correspondence: martoor@doctor.upv.es; Tel.: +593-984-364-210
}

\section{check for} updates

Citation: Toledo-Orozco, M.; Arias-Marin, C.; Álvarez-Bel, C.; Morales-Jadan, D.; Rodríguez-García, J.; Bravo-Padilla, E. Innovative Methodology to Identify Errors in Electric Energy Measurement Systems in Power Utilities. Energies 2021, 14, 958. https://doi.org/ 10.3390/en14040958

Academic Editors: Andrea Mariscotti and Ferdinanda Ponci

Received: 2 December 2020

Accepted: 3 February 2021

Published: 11 February 2021

Publisher's Note: MDPI stays neutral with regard to jurisdictional claims in published maps and institutional affiliations.

Copyright: (c) 2021 by the authors. Licensee MDPI, Basel, Switzerland. This article is an open access article distributed under the terms and conditions of the Creative Commons Attribution (CC BY) license (https:// creativecommons.org/licenses/by/ $4.0 /)$.

\begin{abstract}
Many electric utilities currently have a low level of smart meter implementation on traditional distribution grids. These utilities commonly have a problem associated with non-technical energy losses (NTLs) to unidentified energy flows consumed, but not billed in power distribution grids. They are usually due to either the electricity theft carried out by their own customers or failures in the utilities' energy measurement systems. Non-technical energy losses lead to significant economic losses for electric utilities around the world. For instance, in Latin America and the Caribbean countries, NTLs represent around 15\% of total energy generated in 2018, varying between 5 and $30 \%$ depending on the country because of the strong correlation with social, economic, political, and technical variables. According to this, electric utilities have a strong interest in finding new techniques and methods to mitigate this problem as much as possible. This research presents the results of determining with the precision of the existing data-oriented methods for detecting NTL through a methodology based on data analytics, machine learning, and artificial intelligence (multivariate data, analysis methods, classification, grouping algorithms, i.e., k-means and neural networks). The proposed methodology was implemented using the MATLAB computational tool, demonstrating improvements in the probability to identify the suspected customer's measurement systems with error in their records that should be revised to reduce the NTLs in the distribution system and using the information from utilities' databases associated with customer information (customer information system), the distribution grid (geographic information system), and socioeconomic data. The proposed methodology was tested and validated in a real situation as a part of a recent Ecuadorian electric project.
\end{abstract}

Keywords: electrical energy losses; outlier detection; data analytics; consumption patterns; machine learning; artificial intelligence

\section{Introduction}

Most power utilities in Latin America and Caribean (LAC) make investments to reduce the non-technical losses of energy (NTLs), with scarce success, as they do not properly consider all the external macroeconomic variables, such as the local employment rate and the level of income per family. These variables are difficult to mitigate in our countries because of the lack of policies, laws, and regulations for power distribution systems. This social and cultural inequality becomes a severe issue for power utilities because consumers cannot pay for the electricity service due to lack of financial liquidity, which encourages cheating the measurement systems to reduce the electricity bill. 
As shown in Table 1, the average rate of energy losses in LAC is 15.65\% [1] concerning the energy available in each power utility system; countries such as Honduras, Jamaica, Paraguay, and Venezuela exceed this average. Nevertheless, Ecuador has presented a considerable reduction from $25.04 \%$ in 2008 to $13.03 \%$ in 2018, due to public investments of a technical nature, digitization of electrical power systems [2], and the initiative of academia through the generation of new data analytics models. In contrast, countries like Chile, Peru, Bolivia, and Costa Rica have the lowest energy losses in the region.

Table 1. Non-technical energy losses in LAC.

\begin{tabular}{lcccccccccccc}
\hline Country & $\mathbf{2 0 0 8}$ & $\mathbf{2 0 0 9}$ & $\mathbf{2 0 1 0}$ & $\mathbf{2 0 1 1}$ & $\mathbf{2 0 1 2}$ & $\mathbf{2 0 1 3}$ & $\mathbf{2 0 1 4}$ & $\mathbf{2 0 1 5}$ & $\mathbf{2 0 1 6}$ & $\mathbf{2 0 1 7}$ & $\mathbf{2 0 1 8}$ & Average \\
\hline Argentina & 14.3 & 14.8 & 14.8 & 13.6 & 14.4 & 15.1 & 12.0 & 13.2 & 13.0 & 14.7 & 15.1 & 14.1 \\
\hline Bolivia & 10.1 & 10.1 & 11.2 & 11.0 & 9.9 & 9.0 & 9.4 & 8.9 & 9.9 & 10.7 & 11.0 & 10.1 \\
\hline Brazil & 15.3 & 15.8 & 15.6 & 15.4 & 15.9 & 15.4 & 14.9 & 15.1 & 15.9 & 15.6 & 15.9 & 15.5 \\
\hline Chile & 8.3 & 8.2 & 5.8 & 6.1 & 2.3 & 6.7 & 6.7 & 5.0 & 3.6 & 5.2 & 5.2 & 5.7 \\
\hline Colombia & 13.4 & 12.3 & 12.0 & 11.3 & 11.7 & 10.1 & 10.6 & 12.4 & 9.4 & 7.4 & 10.4 & 11.0 \\
\hline Costa Rica & 10.3 & 10.6 & 10.1 & 10.8 & 10.6 & 10.5 & 10.6 & 12.1 & 10.2 & 9.9 & 9.8 & 10.5 \\
\hline Cuba & 15.9 & 14.3 & 15.9 & 15.8 & 15.7 & 15.3 & 15.3 & 15.5 & 15.2 & 15.5 & 15.8 & 15.5 \\
\hline Ecuador & 25.0 & 21.3 & 18.6 & 17.8 & 15.3 & 14.2 & 12.6 & 12.7 & 13.0 & 12.6 & 13.0 & 16.0 \\
\hline El Salvador & 9.6 & 10.9 & 11.7 & 12.1 & 9.8 & 7.0 & 9.8 & 9.4 & 11.6 & 11.4 & 11.6 & 10.4 \\
\hline Guatemala & 14.1 & 14.4 & 9.8 & 13.2 & 12.5 & 11.8 & 12.4 & 12.0 & 12.1 & 12.6 & 11.7 & 11.5 \\
\hline Honduras & 20.6 & 21.5 & 27.5 & 26.1 & 28.6 & 28.2 & 16.2 & 14.2 & 14.7 & 31.9 & 30.2 & 23.6 \\
\hline Jamaica & 23.3 & 23.2 & 22.5 & 24.5 & 27.2 & 28.0 & 28.5 & 28.5 & 26.6 & 26.3 & 26.0 & 25.9 \\
\hline Mexico & 15.8 & 16.3 & 16.4 & 15.9 & 15.1 & 14.6 & 13.9 & 13.4 & 12.8 & 15.8 & 17.5 & 15.2 \\
\hline Panama & 14.0 & 13.1 & 14.5 & 13.6 & 13.7 & 13.5 & 14.0 & 13.6 & 14.4 & 13.5 & 13.0 & 13.7 \\
\hline Paraguay & 31.8 & 31.6 & 31.5 & 29.8 & 30.6 & 25.9 & 24.5 & 24.6 & 24.9 & 24.9 & 23.6 & 27.6 \\
\hline Peru & 8.2 & 8.1 & 10.2 & 9.6 & 8.2 & 10.5 & 11.0 & 11.0 & 10.6 & 10.5 & 10.9 & 9.9 \\
\hline Dominican & 11.9 & 12.7 & 13.2 & 12.8 & 12.8 & 12.7 & 12.7 & 12.8 & 12.9 & 13.0 & 13.0 & 12.8 \\
Republic & & & & & & & & & 10.2 & 17.0 \\
\hline Suriname & 9.0 & 9.0 & 8.5 & 9.0 & 9.0 & 10.2 & 8.7 & 10.5 & 17.0 & 17.9 & 18.6 & 11.6 \\
\hline Uruguay & 11.1 & 11.5 & 11.6 & 11.9 & 11.6 & 11.2 & 10.7 & 12.0 & 12.2 & 13.1 & 11.5 & 11.7 \\
\hline Venezuela & 26.7 & 27.8 & 27.9 & 29.6 & 31.0 & 32.0 & 32.8 & 32.2 & 29.2 & 29.2 & 29.2 & 29.8 \\
\hline & & & & & & & & &
\end{tabular}

The research is based on applying the concepts and algorithms of data analytics, machine learning, and neural networks to build a systematic methodology to determine changes in consumption patterns and efficiently locating energy thefts to mitigate losses for energy distribution companies.

The review of state-of-the-art shows in general that the techniques used in the analysis of NTLs consider the use of a reduced amount of data with theoretical results; that is, they do not use a combination of techniques to minimize the error in data processing [3,4].

Five different algorithms for NTL detection using Pearson's coefficient, Bayesian networks, and decision trees were developed and tested in [5]. They used a real database provided by Endesa to test the models.

Nizar, A.H. et al. [6] presented a method to determine what type of data provides the highest precision concerning NTL analysis in the electricity distribution sector. The method identifies two popular classification algorithms, naive Bayesian and decision tree, to detect any significant energy consumption behavior abnormality.

Leite, D. et al. [7] took the case of Brazil in their research and defined the efficient frontier model, SFA (stochastic frontier analysis), from stochastic economic, social, and political variables for electric power distribution utilities to provide tolerable limits on the percentage of non-technical losses to mitigate the total cost of the transmission and distribution infrastructure associated with these utilities as an alternative to the econometric approach used in the rate review cycle.

Arthur, D. et al. [8] used only k-means to perform tests in different scenarios, looking for the comparable asymptote or the best result in the evaluation. 
Sun, $\mathrm{S}$ et al. [9] transformed and adapted the traditional nearest neighbor algorithm $(\mathrm{kNN})$ to $\mathrm{k}$ (AdaNN); the value of $\mathrm{k}$ has a crucial influence on the performance of the proposed algorithm; the optimal $\mathrm{k}$ detects the correct class label; and the experimental results indicate that the algorithm performs better than traditional $\mathrm{kNN}$.

On the other hand, Ramos, C.C.O. et al. [10] approached NTL by using artificial intelligence techniques. However, their use can result in a high computational load in the training and parameter optimization procedures. They showed that the pattern recognition technique called optimal path forest (OPF) is superior to the latest artificial intelligence techniques. Comparisons with neural networks and other methods demonstrated the robustness of the OPF concerning the automatic identification of commercial losses.

Nagi, J. et al. [11] presented the inclusion of human knowledge and experience in the fraud detection model based on SVM with the introduction of a fuzzy inference system, in the form of fuzzy IF-THEN rules. It acts as a post-processing scheme to show the suspects with a probability of fraud; the detection rate was between $60 \%$ and $72 \%$.

Likewise, León, C. et al. [12] used an integrated experts system to analyze useful customer information to identify the NTLs and their type. It included text mining modules, data mining modules, and the rule-based expert system module. It was applied to real data from the Endesa company power utility in the testing phase by human experts, providing a tool for the inspectors to make the best decision.

Additionally, Galván, Elices, Muñoz, Czernichow, and Sanz-Bobi [12] proposed a general methodology based on the use of radial basis function networks, with the following steps: (1) selection of variables, (2) data filtering, (3) model fit, (4) model analysis, and (5) model evaluation. The third step takes variables from monthly periods of each pattern of annual consumption and active consumption. The methodology was applied to two sectors: the low voltage residential and high-voltage irrigation sectors.

Similarly, Reference [4] presented a set of rules with a high rate of correct NTL identification based on the most relevant customer attributes available in the distribution companies' database. It allowed a reduction of the number of inspected clients with a fraud identification rate between $7 \%$ and $20 \%$.

The research presented in this paper focuses on NTLs in Ecuador since it is one of the countries in the region with success in reducing and mitigating NTLs, with an investment above 50 million dollars in related projects [13,14].

Electric energy supply from generation to final users implies losses in different processes where the main component is in the distribution stage [15-17]; the losses are the difference between the energy delivered by the generator and the energy measured and billed by the company. They are classified into technical and non-technical losses $[18,19]$.

Non-technical losses, also known in the specialized literature as "black losses" or "commercial losses", are produced by administrative errors generated by the CIS, incorrect readings, errors in the computation of consumption, incorrect energy in end-use, and theft or manipulation of the metering system, among others. Generally, their forecast is uncertain (stochastic nature), since it is not known where, how, and when they occur. They are computed as the difference between the total losses and the technical losses of the distribution system $[18,20,21]$.

NTLs are classified according to their cause $[16,18]$ :

- Theft of energy: Any type of illegal connection that is made before the energy meter so that the connected load consumptions are not recorded by the measurement equipment.

- Handling of the measuring equipment: Voluntary alterations to the measuring equipment resulting in the registration of less consumption than the real one.

- Measurement errors: Involuntary technical failures of measurement devices that produce the wrong recordings, such as:

- Damage to the components of the measurement system in direct and indirect connection,the meter, current transformers, potential transformers, terminal blocks, and connection cables. 
- Human error in taking the reading or failure of the telemetry equipment.

- Incorrect configuration of the energy meter.

- Unintentional errors in the connection of the measurement system installation.

- Billing errors: They occur when the energy consumed is not recorded in the billing system of the distribution company due to damage to the components of the metering system.

The traditional method used by distribution companies to mitigate this problem is periodic random inspections on-site, a method that requires a high amount of financial and technical resources [21-23].

The research presented here aims to ease and reduce the costs associated with this procedure, with the following contributions:

- Development of a methodological study based on suitable indicators that integrate and take advantage of the different technologies for data analytics, machine learning, and neural networks. These results of the study were tested with real utility data related to customers' consumption patterns. This study yields a list of potentially manipulated measurement equipment to be reviewed under the planning of the power utility.

- The study allows identifying which technique gives the best result, denoting the precision of each of these, with the support of data science, processed through the use of the computational tool MATLAB ${ }^{\circledR}$ for the construction of algorithms, in such a way that contributes to the objective of reducing non-technical losses and maximizing economic utility incomes.

This document is structured as follows: Section 2 considers the current state-of-the-art, providing a deep insight into the theoretical concept of the evaluated methods for the determination of NTLs. Section 3 shows the process of data analytics and the application of the algorithms. Section 4 presents the results of the methodology for the proposed analytic methods' evaluation and comparison. Section 5 shows the results of the implementation of the methodology in a real system. Finally, in Section 6, the technical and economic effects are discussed and concluded.

\section{Techniques Applied in Data Mining}

The research is based on the concept of maximizing the probability of finding in the location of measurement systems errors in the recorded data, in such a way that the result of the execution of the algorithm allows reviewing only suspected cases, applying various methodologies as shown in the specialized literature in Table 2. This literature addresses the current issues of supervised and unsupervised data analytics techniques applied to electricity consumption variables. The new data concepts guide methods with algorithms that yield responses with metrics whose errors allow decision-making in the proposed approach.

The methodologies combined in the research are:

1. Theoretical study: This focuses on analyzing aspects related to energy theft through the use of statistical techniques with socio-demographic and socio-economic variables to build potential lists of suspected infractions for the reviewed measurement systems; The disadvantage of theoretical studies is that they do not present specific cases of theft or the failure of the measuring equipment [20].

2. Data-oriented methods: These methods focus on data analytics, for example the pattern of energy consumption and demand. By applying data mining techniques, the consumers with high error probability are identified [20,22].

Learning with data mining techniques is classified into:

(a) Supervised learning: These are algorithms that learn by example, require input data, and provide output data with the variables that the data scientist needs; that is, he/she must give instances on properly labeled data (positive/fraud and negative/no fraud). This method requires a large amount of quality information 
to apply the model; the electricity distribution company must have data labeled with the variables of fraud and not fraud [20,22].

(b) Unsupervised learning: The function of these algorithms is to determine patterns to acquire training according to the available variables; generally, these algorithms use databases whose variables do not have labels or when the sample does not have a sufficient amount of data [20-22].

3. Network-oriented methods: These methods are based the acquisition of data through the management of proprietary software and hardware installed in the electrical network, in such a way as to facilitate the identification or estimation of non-technical losses after a data analytics process through an algorithm that minimizes error and loss of information.

4. Hybrid method: This is a combination of the two classifications mentioned above to maximize the precision in detecting NTLs [20,22].

Table 2. Literature review of the methods used for NTL detection.

\begin{tabular}{|c|c|c|c|}
\hline Methodology & Concept & Algorithm-Method & Reference \\
\hline Theoretical study & & & {$[17,24-26]$} \\
\hline \multirow{13}{*}{ Data-oriented methods } & \multirow{7}{*}{ Supervised learning } & Nearest neighbor (k-NN) & {$[27,28]$} \\
\hline & & Decision trees & {$[4-6,27-31]$} \\
\hline & & Artificial neural network (ANN) & {$[3,31-36]$} \\
\hline & & Support vector machine (SVM) & {$[29,32,35]$} \\
\hline & & Optimum path forest (OPF) & {$[10,27,37]$} \\
\hline & & Bayesian classifiers & {$[5,6,27]$} \\
\hline & & Rule induction & {$[4,5,11,12,33,38]$} \\
\hline & \multirow{6}{*}{ Unsupervised learning } & Self organizing map (SOM) & {$[31,38]$} \\
\hline & & Cluster K-means & {$[21,38,39]$} \\
\hline & & Cluster K-menoids & [21] \\
\hline & & Regression models & {$[27,35]$} \\
\hline & & Fuzzy c-means & {$[38,40,41]$} \\
\hline & & Outlier detection & {$[38,42]$} \\
\hline $\begin{array}{l}\text { Network-oriented } \\
\text { methods }\end{array}$ & & & {$[16,19,43-45]$} \\
\hline \multirow[b]{3}{*}{ Hybrid methods } & & Observer meter-SVM & {$[46,47]$} \\
\hline & & Smart meter-SVM & [48] \\
\hline & & $\begin{array}{l}\text { Smart meter-observer meter- } \\
\text { maximum information } \\
\text { coefficient (MIC) } \\
\text {-clustering technique }\end{array}$ & [49] \\
\hline
\end{tabular}

They are also known as supervised and unsupervised techniques, which will be used later for comparison purposes.

\subsection{Unsupervised Techniques}

$\mathrm{K}$-means is a clustering technique that has the purpose of dividing $n$ number of samples into $K$ number of groups; it is based on the entry of $n$ number of instances, each one defined by a vector (a group of variables) and a number $K$ integer that indicates the number of groups to be developed [8,50,51]. It is a technique that groups samples according to set similarity proximity, defined by " $\mathrm{K}$ " or "centroid" points. The advantage of this 
technique is efficiency when handling large data sets, and as a disadvantage, it is essential to know the number of formed groups. Another disadvantage is the sensitivity to noise in calculating the groups referring to a center; any atypical data could alter this centroid; therefore, low group formation can impair the response [21].

The operation of this technique is shown in Table 3 [8,50].

Table 3. Algorithm for K-means.

1. Randomly enter a value of $K$, these being the centroids of each group.

2. Form K clusters, setting each of data to the closest centroid.

3. Readjust the K centroids, which will be the average of the group established in Step 2.

4. Repeat Steps 2 and 3 until there is no readjustment of centroids.

It can overcome this drawback by knowing the number of groups to be developed. For example, there are several methods, such as the "elbow method", which is a method that analyzes the percentage of variance as a function [50]. Another technique is the gap method (GAP), similar to the elbow method [21,50]. However, no method determines the exact number of clusters to develop; the number of groups is generally chosen by trial and error, always at the discretion of the researcher [21].

\subsection{Supervised Techniques}

\subsection{1. k-Nearest Neighbors}

This is a supervised algorithm, one of the oldest and most straightforward to use for classifying samples [9,22], which classifies the models based on their similarity with other cases, enters a model into the characteristics field, and sets the class that is more common among the closest neighbors. It uses a single parameter called " $\mathrm{K}$ ", which indicates the number of nearest neighbors to test $[9,28,52,53]$.

The algorithm is simple to apply; it calculates the distance between the new elements with the training set, and depending on the $K$ value, it gives a label to the initial value; for example, the $K$ value is five when calculating the closest neighbors to the original sample: four belong to one group and the rest to another; therefore, it can be concluded that the original model belongs to the first group $[9,22]$.

The algorithm is presented in Table 4.

Table 4. K-nearest neighbor algorithm.

1. Enter class data $C=\left(X_{1}, Y_{1}\right), \ldots\left(X_{n}, Y_{n}\right)$.

2. Enter data to classify $N=\left(X_{1}, \ldots, X_{n}\right)$.

3. Enter the value of $K$ neighbors to consider.

4. For every classified object, calculate the distance with the data to be classified.

5. Keep the $K$ training data closest to the data to be classified.

6. Assign $X$ the most frequent class.

\subsubsection{Decision Tree}

This is a process flow that shows the probable results of a series of connected decisions: a hierarchical decision model that starts with a single node and follows a series of rule "branches" into possible results [6,22,54].

A suitable task for the decision tree is classification [22]. It is a supervised method since the information classification uses a predefined data set with classes, according to the variables [6]. First, it obtains useful information from each attribute (variable), known as information gain. The attribute with the highest information gain will be the initial node or root node. It will divide into different branches based on the values of the node [6,28,54].

Several algorithms are used for creating decision trees, including ID3, C4.5, CART, and CHAID. The criterion of partitioning distinguishes each one; for example, CART is characterized by generating binary trees and uses the dosing criterion for the division of 
its nodes; ID3 uses the information gain as a division criterion; C4.5 uses the gain ratio as the division criterion. The division stops when the number of instances divided is below a certain threshold [54].

\subsubsection{Artificial Neural Network}

Inspired by the neurons in the human brain, this deals with linked layers that take the shape of a neuron, relating input data with output data, learning from the data, looking for patterns, classifying data, and predicting future events $[22,36,55]$.

It is a supervised method that receives training through examples. There are many types of neural networks, but for classification cases, multilayer perceptron is usually used, which uses a supervised technique called backpropagation [36]. Figure 1 shows the basic structure of this neural network, and as we can see, it consists of three layers: input layer, hidden layer, and output layer. The connections between neurons transmit the signals. In the input layer, it receives the signals and distributes the information to the next layer (hidden layer). The number of neurons in the input layer will be equal to the input vector (number of attributes). The hidden and output layers process the signals by amplifying, attenuating, or inhibiting the signals. The number of neurons in the output layer will be equal to the number of classes in the investigation; the number of neurons in the hidden layer will depend on the application for which the neural network is established $[32,34,36]$.

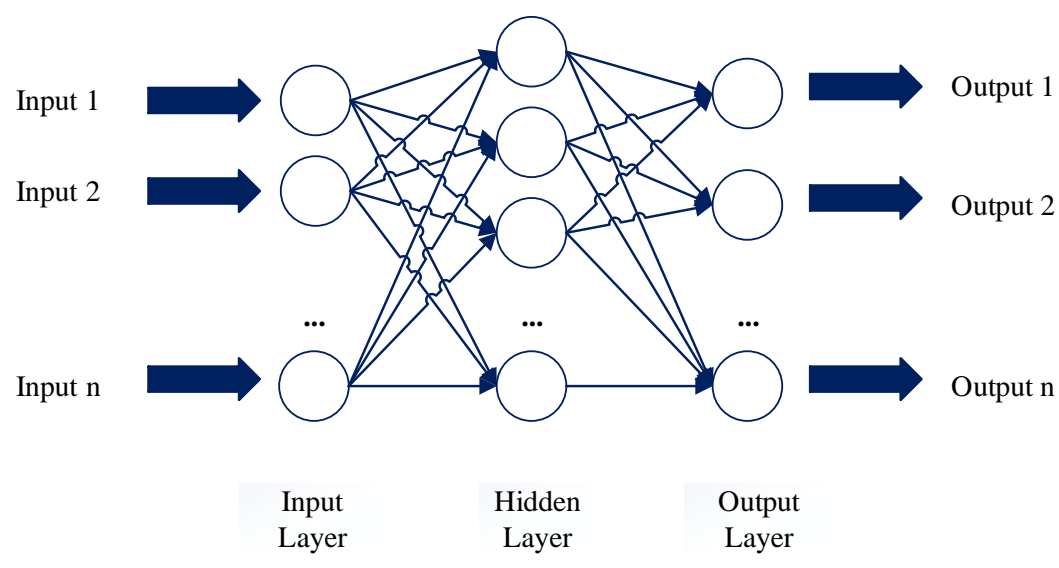

Figure 1. ANN structure.

Except for the input nodes, each node in the hidden and output layers is a neuron that uses an [34,36] activation function.

The establishment of a neural network consists of three stages [36]:

1. Training stage: This is the learning stage where the input attributes (network input) can be added and compared with the target set (label or target).

2. Validation stage: This stage is executed in conjunction with the training stage and is carried out to avoid over-training the network.

3. Testing stage: This stage is carried out after the training stage and consists of using a set of data other than those of the training and validation stage to investigate how well the network learned at the end of the process.

The exposed techniques were used in the comparative analysis carried out in this research to determine the consumption patterns and energy losses.

\section{Methodological Construction of the Matrix and Data Analysis}

The methodology's objective allows establishing a comparison of the different data analytics techniques in a systematic way to evaluate the non-technical energy losses of a 
distribution company through the recognition of the consumption patterns and to ascertain potential thefts of energy.

The input variables used in the model come from different databases, both from the CIS, GIS, and distribution companies. Besides, the external information corresponds to the National Institute of Statistics and Census of Ecuador.

\subsection{Data Collection and Integration}

The information required for integration came from the company's reports; these correspond to energy losses in a period of 18 months, financial indicators, final energy use profiles, date of the last review of the measurement systems, year of manufacture of the energy meter, outstanding debt, outage status, and consumption range. A large part of these variables came from the system application product (SAP). Furthermore, related information was taken from the GIS, such as location, load density per square meter, consumption stratum, type of electrical networks, social stratum, among other variables.

Figure 2 describes how the data matrix called the "base matrix" was obtained from the variables used in this research.

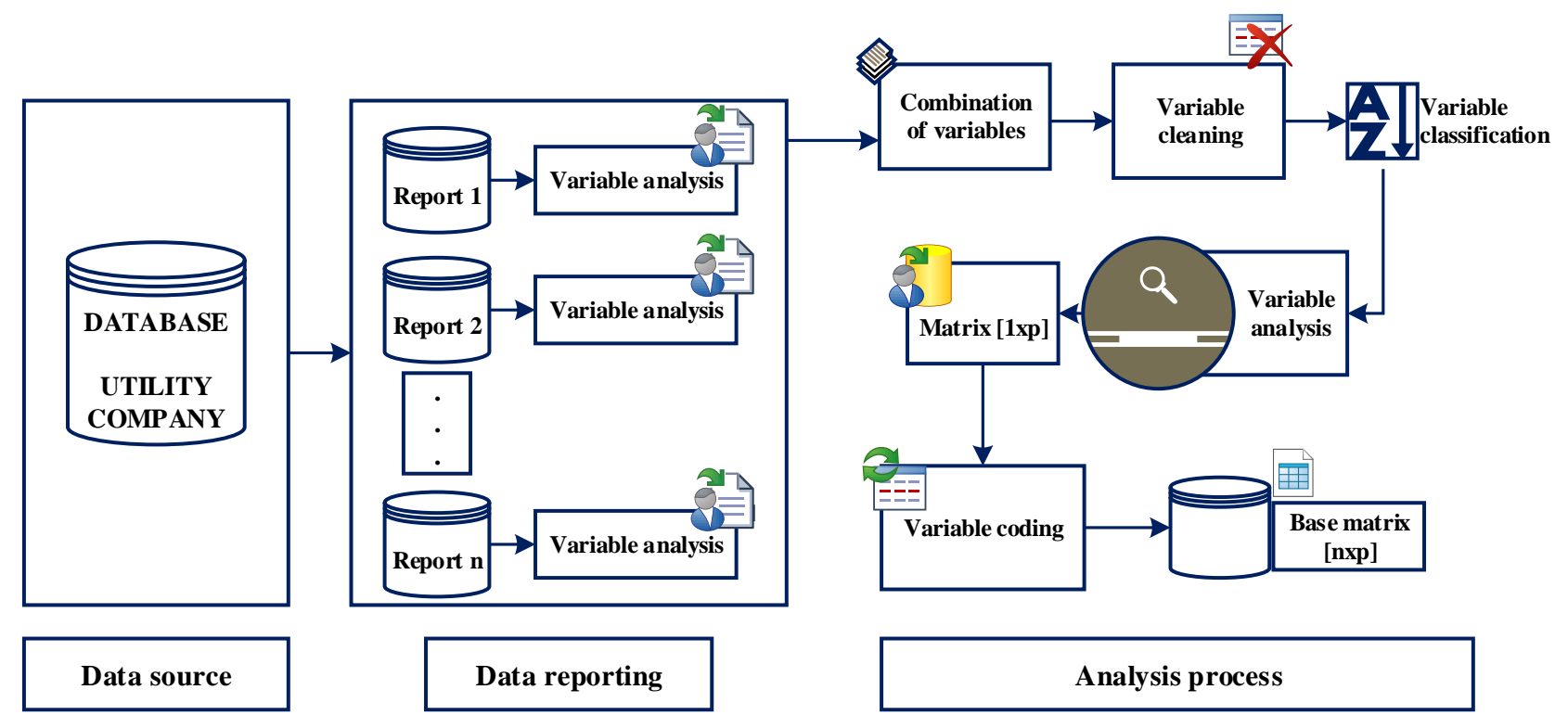

Figure 2. Data collection and integration process.

1. Integration of the data set: In this step, this is the most important or relevant data in the search; allows determining the NTL according to the history of consumption, demands, consumer characteristics, and type of meter.

2. Variable analysis: The variables of each report are analyzed, understanding that they describe the type of information each variable contains.

3. Combination of variables: All the reports are joined, obtaining 424 variables in this investigation.

4. Variable cleaning: Variables with the same name and with different names, but with the same information content are eliminated because they do not contribute to the model and increase the computation time of the algorithm and the error in the result. Once completed, these steps have 318 variables.

5. Classification of the variables: The variables are classified as follows:

- Information: Those variables that provide consumer information, such as: "contracted account", "account", "name", and "ID."

- Geographic: Variables that indicate the geographic location of the customer's meters, such as: "Codparr", "province", and "canton." 
- Economic: Variables that show the economic relationship between the customer and the distribution company, such as: "date last paid", "months due", and "debt."

- Social: Variables that indicate a social aspect concerning the client, such as "population."

- Techniques: Technical variables, such as: "type consumption", "voltage”, "consumption kWh/month."

With the classified variables, the next step corresponds to the careful review of each variable to determine those that provide relevant information in the NTL detection and control algorithm. Subsequently, with the correlation analysis of the variables and the "expert's criteria", each variable is meticulously analyzed to establish the number and magnitude of the variables that will provide information to this research methodology. After completing this step, we have 68 variables: a matrix $[1 \times 68]$ that eliminates approximately $84 \%$ of the variables that do not contribute, repeat, or have a high variation coefficient. Steps $2,3,4$, and 5 are developed under the supervision of an expert.

6. Data coding: As the variables that make up the $[1 \times 68]$ matrix were obtained from different reports, they do not have the same format; therefore, in this step, some variables are coded for the analysis.

7. Base matrix: With the previously performed analysis, the $n$ subscribers can be added, and the base matrix of size $[n \times p]$ is obtained; where $n$ represents the number of customers; in a first approximation, a universe of 5615 consumers is taken (only for analysis); concluding with a base data matrix of [5615 × 68].

\subsection{Data Pre-Processing}

This step is essential for applying any data mining technique. It allows eliminating or separating anomalous data so that the matrix remains in optimal conditions for training through any method, whether supervised learning or not. For the pre-processing of the data, Variables 1 to 26 are omitted since these variables provide customer information (name, contract, telephone). The analysis is carried out from Variable 27 onwards because technical data refer to the consumer (consumption, demands, invoiced values).

\subsubsection{Recognition of Data}

The CIS tries to minimize the entry of wrong information; however, it is inevitable to have this information in the data matrix, causing the variables to move away from the mean and lose their nearness to reality, distorting the analysis context. The research placed null and white values in the data matrix; these are considered in the analysis as outliers; these are discarded in the execution of the data analytics techniques. Additionally, the recognition of technical variables is carried out through exploratory analysis to identify patterns that allow future actions to make decisions.

The statistical indices of the different variables are in Table 5. The Null data column presents values with 255 errors observed in the records of a universe of 2462 consumers; This effect begins with the migration of information from the previous AS400 (Servers Storage Systems)system to the new SAP CIS-CRM. As indicated in the last paragraph, outliers remain in the analysis of this investigation as they could be false positives.

From the analysis using descriptive statistics, the following are determined:

- All variables presented blank or null data.

- There exist large differences between the maximum and minimum values; there are even high percentages of the variation coefficients, generally occurring when the base matrix analyzed contains measurement systems with information of residential, commercial, and industrial consumers; therefore, consumption varies considerably. The data must be linearized and normalized to reduce these differences in values and avoid possible errors in training and executing the algorithms; this procedure is given in Section 3.2.3. 
- Some variables have negative values; the distribution company states that they correspond to re-invoicing of the consumer due to reading errors or low application rates.

- The zero value for the mode in the consumption variables determines that there are measurement systems with zero consumption; it is essential to physically review this in field planning.

- There is a high difference between the maximum and minimum values; this must be considered when applying data mining techniques.

In Figure 3a, the data dispersion of the variable "consumption" and, in Figure 3b, the variable "debt" respectively, are given; The negative values (enclosed in red) are due to the dispersion of the variables of the database considered in this investigation.

Table 5. Data analysis using descriptive statistics.

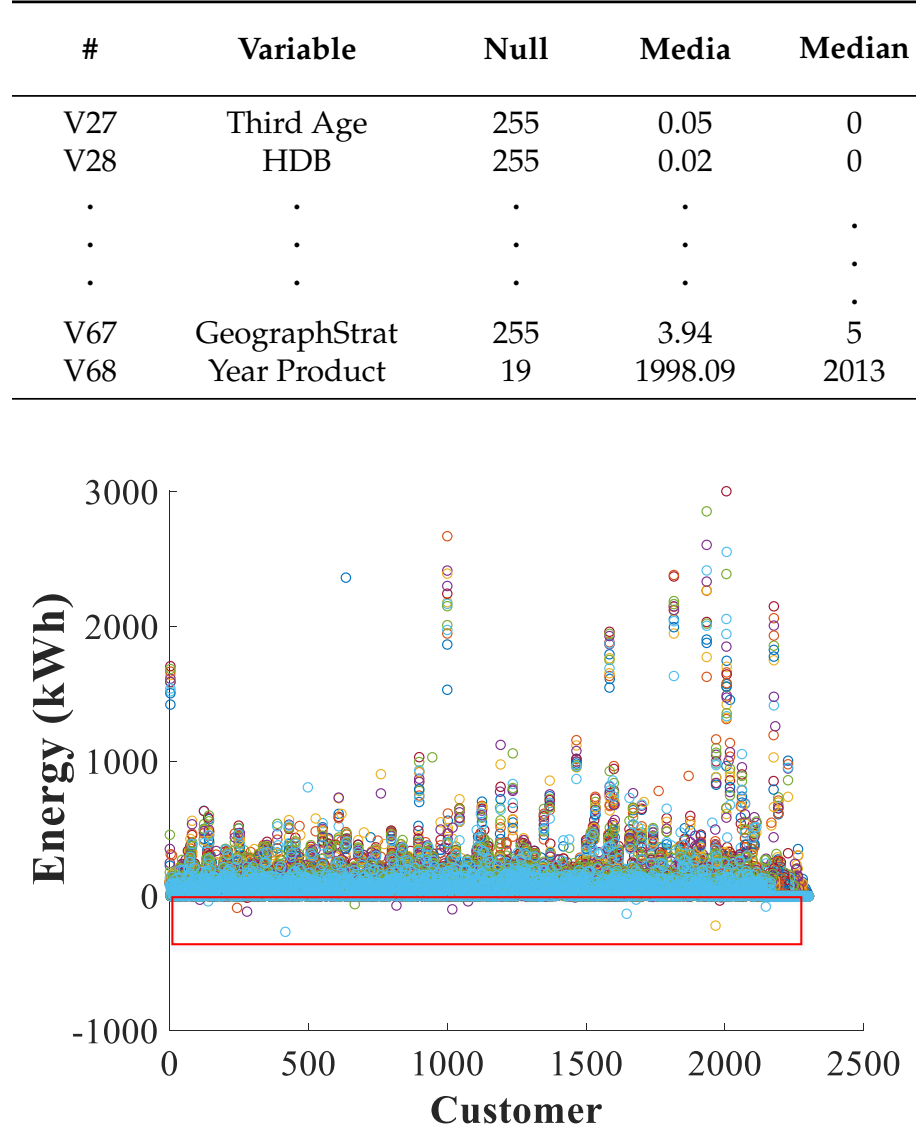

(a)

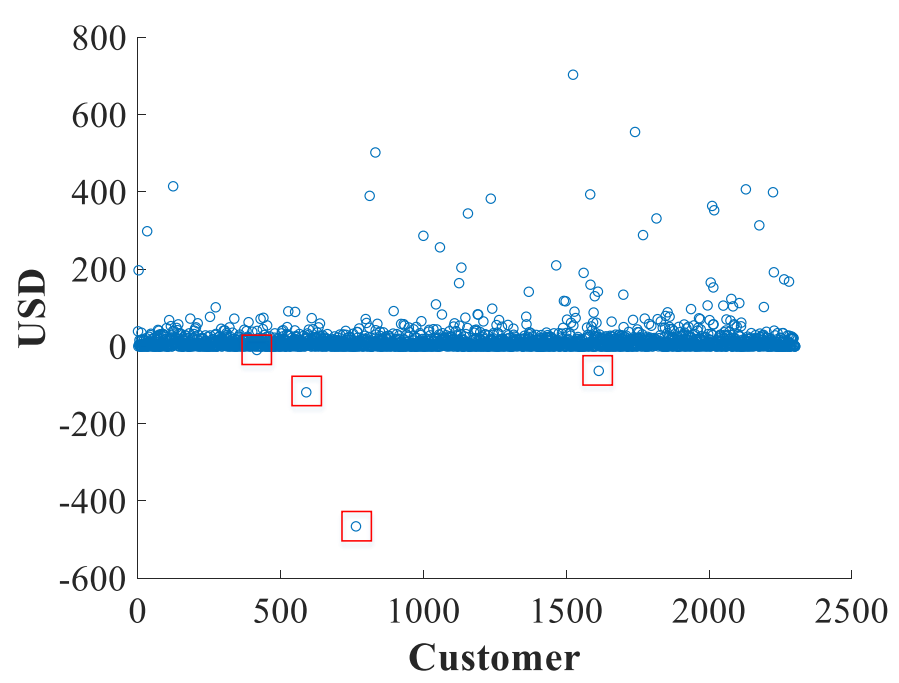

(b)

Figure 3. (a) Data dispersion of the energy consumption variable; (b) Data dispersion of the debt variable.

\subsubsection{Data Cleaning}

One of the main points of this research is the cleanliness of the data since the information comes from different bases and may suffer alterations in the handling and transfer from the source, so it is suggested to maintain greater care, or failing that, to use tools like business intelligence (BI) for information management. The tools used for cleaning the data were Microsoft EXCEL and MATLAB ${ }^{\circledR}$, according to the following process:

- Null or non-existent data are verified:

- $\quad$ EXCEL recognizes the missing data as N/A.

- $\quad$ MATLAB $^{\circledR}$ recognizes non-existent data as NaN (not a number). 
Those consumers that have null data in the technical variables are eliminated from the list.

- $\quad$ Atypical data: Through exploratory data analysis, it is determined that the data that should have been considered inconsistent are the negative values in the technical variables; therefore, any consumer that has a negative value is eliminated from the list.

\subsubsection{Data Normalization}

The variables studied in the research present coefficients of variation with high ranges, so it is necessary to center, scale, or linearize the data to be in the same range.

The normalizations used are:

- Maximum-minimum normalization: This is done by Equation (1).

$$
v^{\prime}=\frac{v-\min }{\max -\min }
$$

where:

- $\quad v^{\prime}$ is the new value

- $\quad v$ is the value to normalize

- $\quad \max$ is the maximum value of the data

- $\quad \min$ is the minimum data value

- $\quad$ Z-score normalization: This is done by Equation (2)

$$
v^{\prime}=\frac{v-\text { mean }}{\text { std }}
$$

where:

- $\quad v^{\prime}$ is the new value

- $\quad v$ is the value to normalize

- mean is the data average

- $\quad$ std is the standard deviation of the data

\subsection{Data Processing}

In this section, the data mining techniques depend on the information available in the matrix created in the utility database. The research objective is to identify which techniques best respond to the data analysis, for which supervised and unsupervised learning techniques are used.

\subsubsection{Supervised Learning}

For the application of supervised methods, examples require training; for this, a database of 2462 samples was obtained, which was reviewed in situ, including 1231 proven instances of fraud and 1231 of non-fraud. Based on the above, the variables used for training are those shown in the following Table 6.

Table 6. Description of the variables.

\begin{tabular}{lll}
\hline$\#$ & Variable & Description \\
\hline$x_{1}$ & Average & 13 month average energy consumption \\
$x_{2}$ & Standard deviation & Standard deviation corresponding to monthly energy data \\
$x_{3}$ & Coefficient of variation & Expresses the standard deviation as a percentage of the average \\
$x_{4}$ & Minimum & Minimum consumption value of the 13 values \\
$x_{5}$ & Maximum & Maximum consumption value of the 13 values \\
$x_{6}$ & Range & Difference between the maximum and minimum value \\
\hline
\end{tabular}


Examples of fraud are labeled " 1 ", and non-fraud examples are labeled " 0 ". Of the 2461 examples, two-thousand sixty-one examples are use for training, and four-hundred are used in the evaluation to identify which provides the best results.

The monitored methods implemented are:

1. Nearest neighbor (K-NN):

The algorithm uses the MATLAB ${ }^{\circledR}$ tool; in Figure 4, the algorithm execution response is given. The training data represent a circular form, and the new data are in a grid form; in red color, data classified as "fraud" and in blue color "no fraud." The K value is five, and the operation of this algorithm is simple; it calculates the distance of the most frequent nearest neighbors (in this case, five) and chooses the class.

Before training this algorithm, the data are normalized with Equation (1).

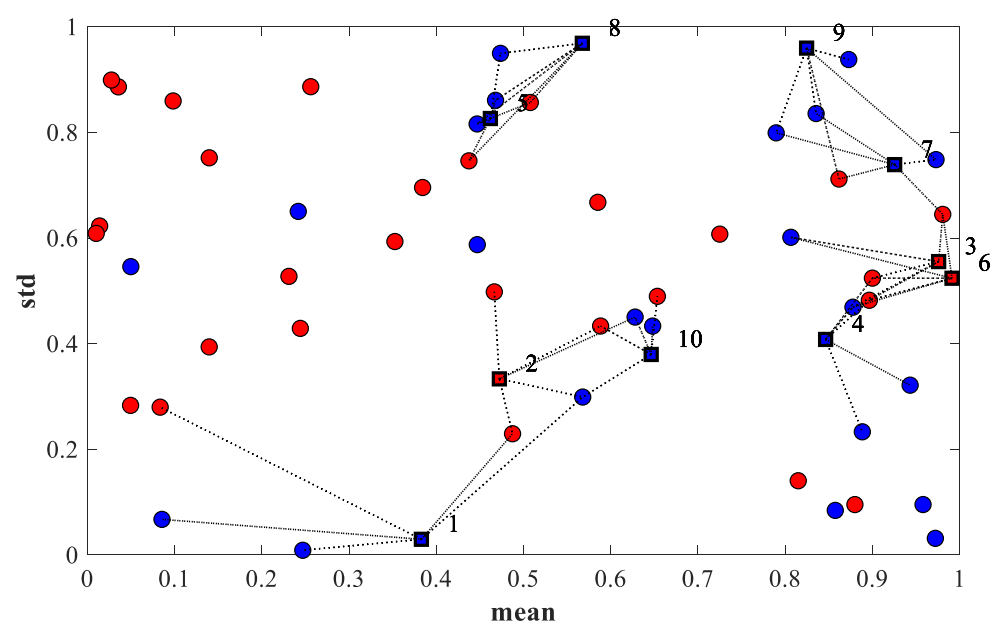

Figure 4. K-nearest-neighbor (K-NN).

2. Decision tree:

The algorithm is executed with MATLAB ${ }^{\circledR}$, generating CART-type decision trees; that is, each node is divided into two. The data are normalized using Equation (1) before training, and the decision tree generated is given in Figure 5.

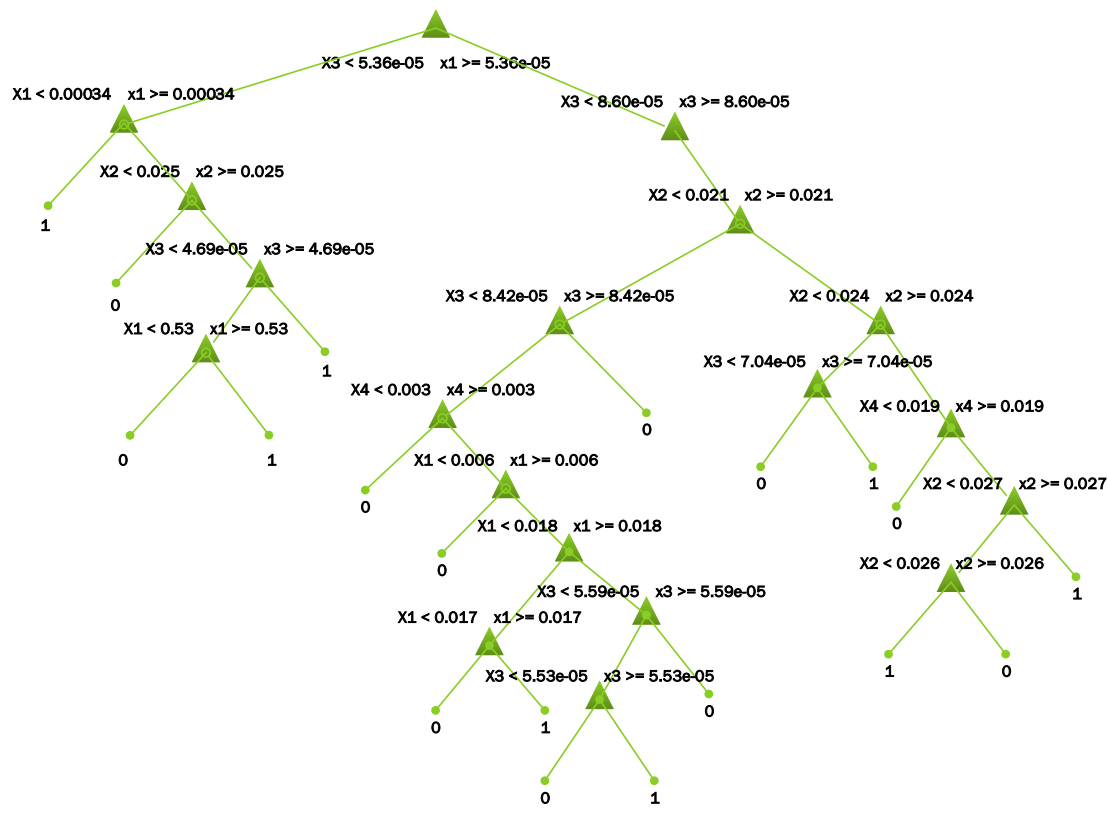

Figure 5. Decision tree. 
3. Neural network (ANN):

The creation and training of the artificial neural network occur using the Toolbox tool of MATLAB ${ }^{\circledR}$, in which the perceptron multilayer neural network is used. The implemented neural network in Figure 6 shows an input layer with six variables; a hidden layer made up of 10 neurons and an output layer with one neuron for classification. The training algorithm is the Levenberg-Marquardt backpropagation, and the activation function is the sigmoidal one.

The data are normalized with Equation (1) and randomly divided into three parts: $70 \%$ for training, $15 \%$ for validation, and $15 \%$ for testing.

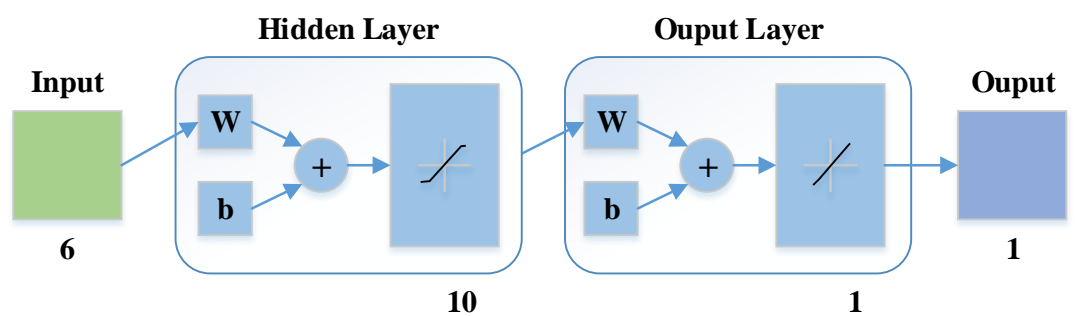

Figure 6. Artificial neural network (ANN).

\subsubsection{Unsupervised Learning}

Unlike previous techniques, "unsupervised methods" do not need examples for training. The technique applied is the following:

1. K-means:

The algorithm does not require following the traceability of previous occurrences; the variables of the base matrix is used; however, only the variables mentioned in Table 6 are used compared with other techniques. The K-means technique is based on grouping by similarities. The algorithm performs a pre-grouping before performing the K-means groupings to avoid bad group formation since the magnitudes of consumption between these rates vary significantly. The data are normalized with Equation (2).

In Figure 7, an example of the algorithm execution is given; the value of $\mathrm{K}$ is two, representing the formation of two groups within the residential rate, the group of fraudulent consumption, and the group of consumers that reflect consumption patterns without alterations. In this sense, it is necessary to plan the on-site review of the measurement systems since something is happening with these measurement systems. An example is presented in Figure 7b. The group is selected as Fraudulent Number 2 (blue color).

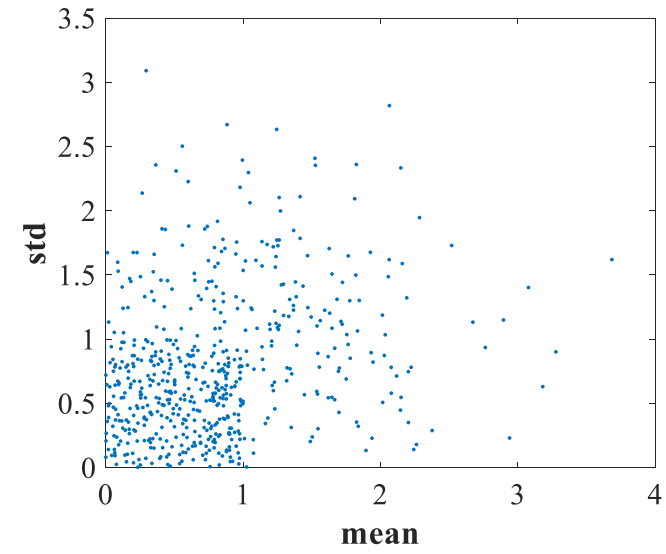

(a)Data

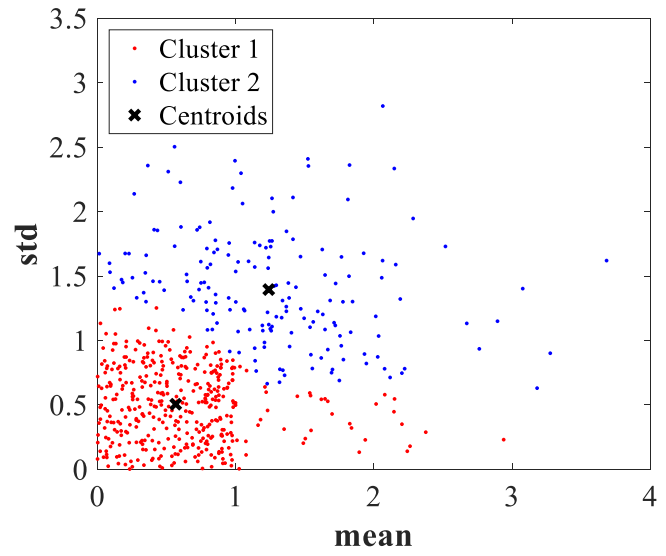

(b)Cluster K-means

Figure 7. Residential ratefor cluster K-means. 


\section{Results of the Application of the Data Analytics Techniques}

Data analytics techniques' performance is analyzed with the data matrix with 400 examples of proven fraud and non-fraud measurement systems, including 200 labeled 1 (fraud) and 200 as 0 (no fraud). From this information, the metrics from the confusion matrix shown in Table 7 are used [5].

Table 7. Confusion matrix.

\begin{tabular}{|c|c|c|c|}
\hline \multicolumn{4}{|c|}{ Actual Values } \\
\hline \multirow{3}{*}{ Predicted Values } & & Fraud (1) & No Fraud (0) \\
\hline & Fraud (1) & $\mathrm{TP}$ & FP \\
\hline & No Fraud (0) & FN & $\mathrm{TN}$ \\
\hline
\end{tabular}

Where [20-22]:

- True positive (TP): when a consumer commits fraud and the technique classifies it as such;

- True negatives (TN): cases correctly cited as non-fraud;

- False positive (FP): when a consumer does not commit fraud and the technique classifies it as fraud;

- $\quad$ False negatives (FN): when a consumer commits fraud and the technique classifies it as non-fraud.

From the confusion matrix presented in Table 7 , the concepts of specificity and reliability are derived [21,22]:

- $\quad$ Specificity or true positive ratio (TPR): This indicates whether a classification technique performs correctly, stating the proportion of samples cataloged as non-technical energy losses corresponding to the total number of non-technical losses within a data group, shown in Equation (3).

$$
T P R=\frac{T P}{T P+F N}
$$

- Reliability or a false positive ratio (FPR): This indicates the relationship between false alarms (consumers falsely classified as committing fraud) and the total number of true negatives, shown in Equation (4).

$$
F P R=\frac{F P}{T N+F P}
$$

Compliance with data analytics techniques is compared based on specificity and reliability metrics. Table 8 shows the result of the evaluation of the $\mathrm{K}$-means technique. Intuitively, two groups should exist, that is $K=2$ (fraud and not fraud); however, the results cannot be right; that is why the technique evaluates different values of $K$.

Good results are obtained when forming 2, 3, 5, and 7 groups, getting high numbers of TP and TN and low numbers of FP and FN; with this, a high percentage of the TPR and a low percentage of FPR are obtained; while with nine groups, the result was in the middle. The results were right, it could happen that in other cases with fewer or more groups, good or bad results are achieved; that is, there is no precise method that determines the right number of groups and which of them to choose as fraudulent; these depend on the amount of data and the number of groups available. In this case, the expert, based on his/her experience, must locate the best group.

Table 9 presents the results of evaluating the K-nearest neighbors technique with different $K$ values; the good results during the application of this technique are from the group $K=10$; this value applies to the corresponding analysis. 
Table 8. Evaluation with metrics of the K-means method.

\begin{tabular}{ccc}
\hline $\mathbf{N}^{\circ}$ of Groups & $\begin{array}{c}\text { TPR } \\
(\mathbf{\%})\end{array}$ & $\begin{array}{c}\text { FPR } \\
\text { (\%) }\end{array}$ \\
\hline 2 & 80 & 17 \\
3 & 80 & 24 \\
5 & 79 & 24 \\
7 & 79 & 24 \\
9 & 49 & 24 \\
\hline
\end{tabular}

Table 9. Evaluation with metrics of the K-nearest neighbors method.

\begin{tabular}{ccc}
\hline K & $\begin{array}{c}\text { TPR } \\
(\mathbf{\% )}\end{array}$ & $\begin{array}{c}\text { FPR } \\
(\mathbf{\%})\end{array}$ \\
\hline 2 & 13 & 62 \\
3 & 16 & 62 \\
5 & 24 & 56 \\
10 & 33 & 53 \\
20 & 25 & 82 \\
\hline
\end{tabular}

Table 10 presents the results of the evaluation with the metrics of the supervised techniques. It shows that the technique that presented the best results in the three methods was the neural network. The neural network obtained considerable percentages of the TPR; however, it presented high values of the FPR $(43 \%)$, indicating that there is a high number of false positives.

Table 10. Metric evaluation of the supervised methods.

\begin{tabular}{ccc}
\hline Methods & $\begin{array}{c}\text { TPR } \\
(\mathbf{\% )}\end{array}$ & $\begin{array}{c}\text { FPR } \\
\mathbf{( \% )}\end{array}$ \\
\hline K-nearest neighbors $(\mathrm{K}=10)$ & 40 & 39 \\
Decision tree & 40 & 63 \\
Neural network & 60 & 43 \\
\hline
\end{tabular}

Comparing the results of data analytics techniques, the K-meansgrouping is the one that delivered the best results; however, it must be taken into account that the training of supervised techniques requires having a database with at least $30 \%$ examples.

An evaluation was performed by applying in the same analysis process an unsupervised technique (K-means) and a supervised technique to determine the measurement systems considered as fraudulent. The result of the evaluation is presented in Table 11.

Table 11. Results of combining K-means with a supervised method.

\begin{tabular}{ccc}
\hline Methods & $\begin{array}{c}\text { TPR } \\
(\mathbf{\%})\end{array}$ & $\begin{array}{c}\text { FPR } \\
\text { (\%) }\end{array}$ \\
\hline $\begin{array}{c}\text { K-means }+ \\
\text { K-neighbors }(\mathrm{K}=10)\end{array}$ & 53 & 34 \\
\hline $\begin{array}{c}\text { K-means + } \\
\text { decision tree }\end{array}$ & 55 & 39 \\
\hline $\begin{array}{c}\text { K-means + } \\
\text { neural network }\end{array}$ & 87 & 16 \\
\hline
\end{tabular}

For the evaluation of the different techniques applied in this research, two groups were used for K-means, as shown in Table 11; when combining the techniques, a better result was obtained, where the TPR percentages increased, although the FPR decreased 
relatively. In Figure 8, the AUC of all the methods implemented in the analysis presented shows that the K-means method was the one that gave the best results. Of the combinations performed, K-means with the neural network turned out to be the most efficient, presenting the highest AUC value among the classification methods.

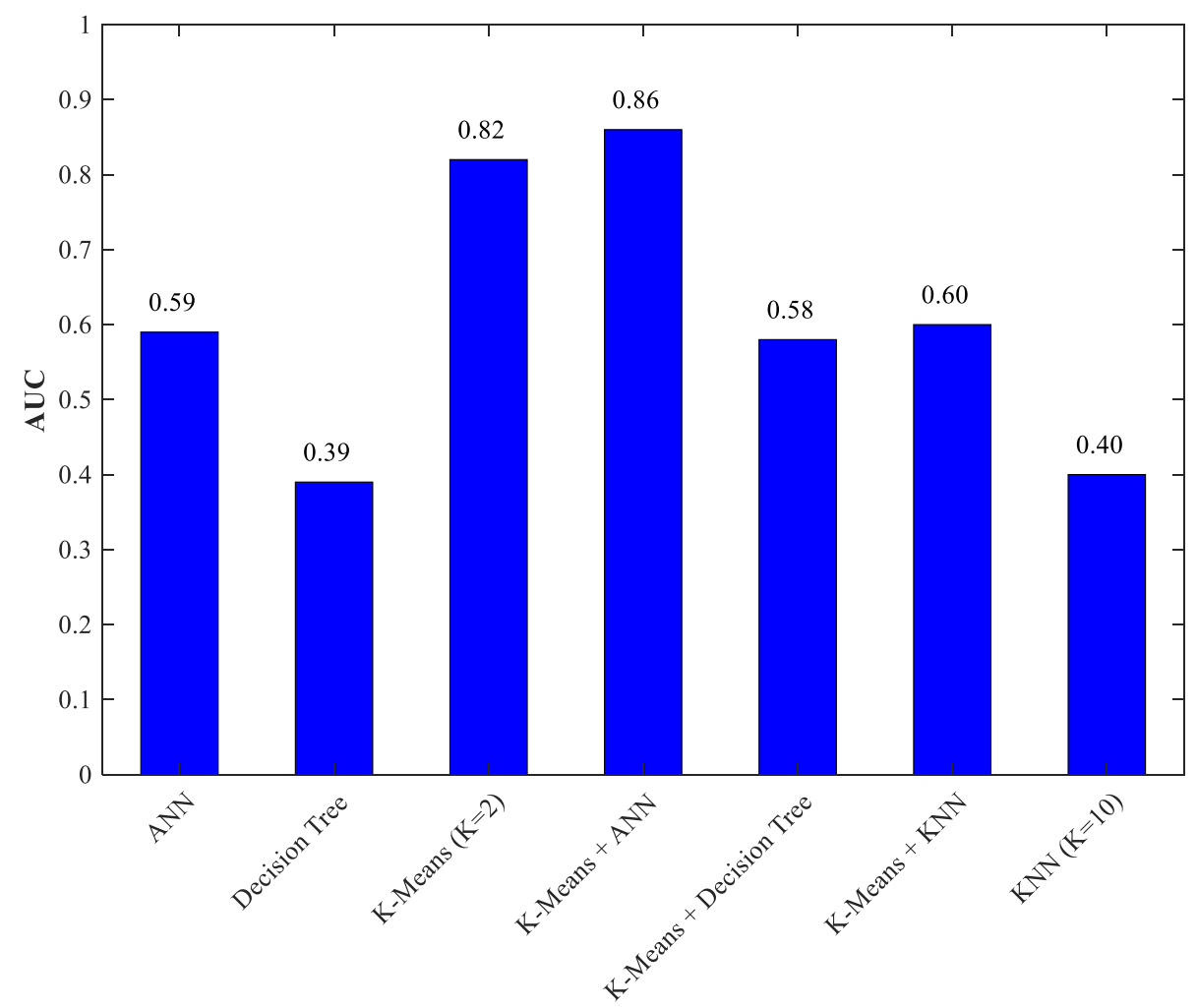

Figure 8. AUC for all classifying methods.

The results are precise; after that information transforms into data through supervised and unsupervised techniques, the advantages arise; these allow the distribution companies to make profound decisions regarding the measurement systems, always focused on economic recovery.

The result of the combination of the k-means and neural network algorithms gave us $87 \%$ true positive data; this value depends on the type of variables used in the analysis, the quality of the information, and the percentage of NTLs that the distributor maintains in their indicators. In the case of distribution companies with high loss rates, the results will be better in practice. The algorithms cited in this research are the most optimal for this analysis.

\section{Case of Study-Application of the Methodology to Determine Energy Losses}

\subsection{Control of Measurement Systems in Utilities}

Generally, utilities have a specialized department for the control and review of the measurement systems; this work is carried out under planning to organize and optimize the inspection of the measurement systems in such a way that establishes precisely the operation and integrity of the measurement systems, guaranteeing correct billing to consumers.

The application of data analytics techniques in distribution companies is almost nil. Therefore, the research proposes applying this new concept to detect fraud or damage to measurement systems, so we applied and tested the algorithms developed with the CENTROSUR Utility data. 


\subsection{Management in the Recovery of Energy Consumed and Not Invoiced}

The methodology results are evaluated based on on-site reviews to determine potential consumers with energy theft during the trial period. In a universe of 15,000 measurement systems, the first results obtained were 1816 reviews; of these, we detected 78 measurement systems with damage and alterations. Under these test conditions, the efficiency of the algorithm was $4.29 \%$, a relatively optimistic value since the non-technical losses in the distribution company did not exceed $0.85 \%$ of the total losses $(6.25 \%)$.

While the economic incorporation with the monthly billing for the energy consumed and not invoiced represented a total value of USD 80,869, this value is due to re-billing processes duly protected by the Organic Law of the Public Electricity Service. In this way, the economic flow of the specialized department can be cover by the management carried out through the recovery of the energy consumed and not invoiced.

\subsection{Examples of the Application of the Methodology for the Reduction of Non-Technical Losses}

The technique's success goes hand-in-hand with the timely revision executed in the measurement system; we will explain some application cases that the execution of the algorithm presents as a result.

With the support of the geographic information system tool, the analysis area was determined using the polygon method to obtain the model's input variables, as indicated in Figure 9.

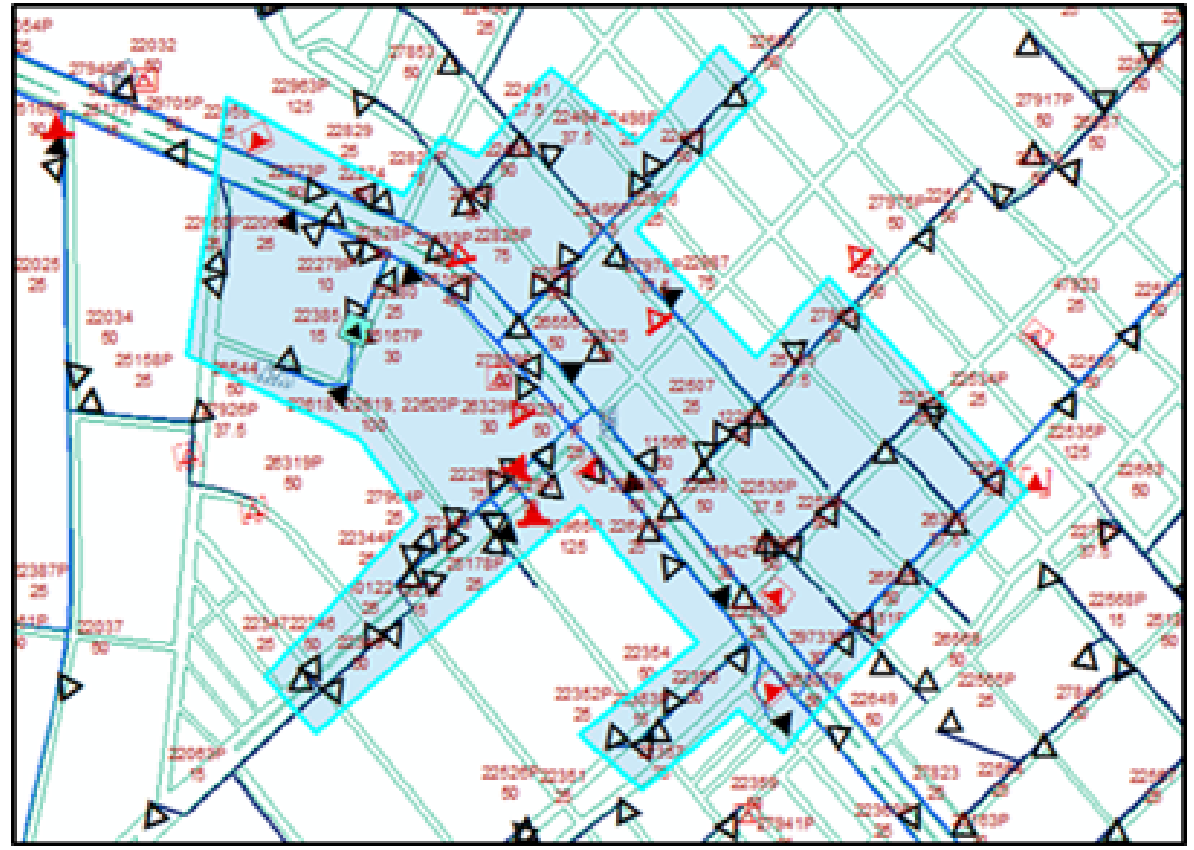

Figure 9. Polygon method of consumers in the group that need to be reviewed.

The measurement systems that presented anomalies in the monthly records are shown in Figure 10. The patterns of electric energy consumption show before and after the anomalous detection resulting from this investigation to recover the energy consumed and not billed. Figure 10a represents the regularization of the indirect measurement system, CL 20 , FM 4 S, installed with medium voltage $(22 \mathrm{kV})$ with a particular transformation station of $25 \mathrm{kVA}$, which maintained a consumption pattern of close to zero since the energy meter had not appropriately configured the current transformer transformation ratio.

In the polygon of Figure 9, there are 1809 measurement systems among residential, commercial, and industrial rates. In this database, it was found that $11 \%$ correspond to atypical data (erroneous and $\mathrm{NaN}$ ), resulting in a list of 1610 . The K-means grouping algorithm was executed in this database, and then, the classification was performed using the neural network, determining that 27 measurement systems qualified for an on-site review. 
Figure $10 \mathrm{~b}$ refers to installing a connection without metering from of public medium voltage network in a particular transformer station of $50 \mathrm{kVA}$. In this case, the meter was removed for non-payment in the last few years. When starting a new project, consumers connected directly so that once executed, the algorithm detected the violation, a measurement system was installed, and energy consumption was re-invoiced. The utility recovered around $750 \mathrm{kWh} /$ month on average.

The example shown in Figure 10c represents the decrease of a consumer in a time window (March 2017 until December 2017); the evidence is in the drop in consumption to zero due to the installation of direct lines; this clandestine connection prevents the energy meter from correctly registering consumption. It detected that around $750 \mathrm{kWh} / \mathrm{month}$ were lost for 10 months.

In the execution and test of the algorithms, through the k-means cluster, we obtained different groups of consumers; one of these is the industrial consumers, significant for the utilities due to the consumption. For this example, Figure $10 \mathrm{~d}$ shows industrial consumers who kept a fault in a voltage transformer of the three existing ones in the measurement system. This decompensation of the magnitude of the voltage in the transformer's delta connection caused the error computed to be more than $47 \%$. Therefore, the window of time to re-bill was wide, more than seven years. However, the law allows only computing one year. In this manner, it recovered around $1950 \mathrm{MWh}$ /year; in economic terms, this corresponded to USD 156,000. In this case, these are important amounts to a utility.

The algorithm no only identifies the fault or the meter being altered, it recognizes the variation of consumption as the function of an in-depth analysis of different variables. Moreover, the algorithm operation allows separating the clusters not identified as altered. The next example shows a load profile with a decrease of consumption, but without fault or alterations; the event is produced for the season of the service zone; generally, the commercial consumer does not use the air conditioning during these seasons, as shown in Figure 10e.

The last Figure $10 \mathrm{f}$ explains another form of consumption variation. It shows a residential consumer's sporadic consumption; generally, his/her home is on the beach or far from the city, and he/she visits it occasionally.

In summary, with the application of the algorithm, the recovery of energy was consumed and but not invoiced was 2,021,800 kWh/year; an USD 161,744 recovery. This information was taken from the marketing system of the energy distribution company.

Distribution companies in LAC do not have remote, real-time measurement systems or advanced measurement infrastructure. Generally, the readings, review, and control of the measurement systems are managed by humans, requiring considerable investments, prolonged times in periodic reviews, and for some, even the change from conventional conductors to pre-assembled, with low success rates.

The percentages of non-technical losses may vary from one country to another, even between regions; for this reason, it is important to treat the information of each of the distributors in a personalized way. This document contributes significantly to the little exploited topic of the automatic analysis of available customer information for NTL detection. The proposed approach presents advantages in the methodology; it uses 68 variables among technical, economic, social, linearized, and correlated data. The information is homogeneous, to later apply supervised and unsupervised methods in the grouping according to the similarity of the data. The different techniques applied were evaluated through metrics to obtain the highest probability of potential energy theft events.

On the other hand, it does not require significant investments; since the data are stored and available, the post-analysis management will use the same infrastructure resources and existing distributor personnel. The methodology carries out continuous learning each time the algorithm is executed; it learns from the real expert data and stores them for future runs of the algorithm to increase certainty in detecting anomalies. Moreover, a set of rules that are executed one-by-one is not required; the expert's criteria are internalized in the algorithm's learning, separating consumers with NTLs from those with true zero or false 
intakes (typical cases). The advantage of applying this methodology is for the distributors with very low percentages of losses $1 \%$ or $2 \%$; therefore, detection will considerably reduce operating costs, achieving technical efficiency.

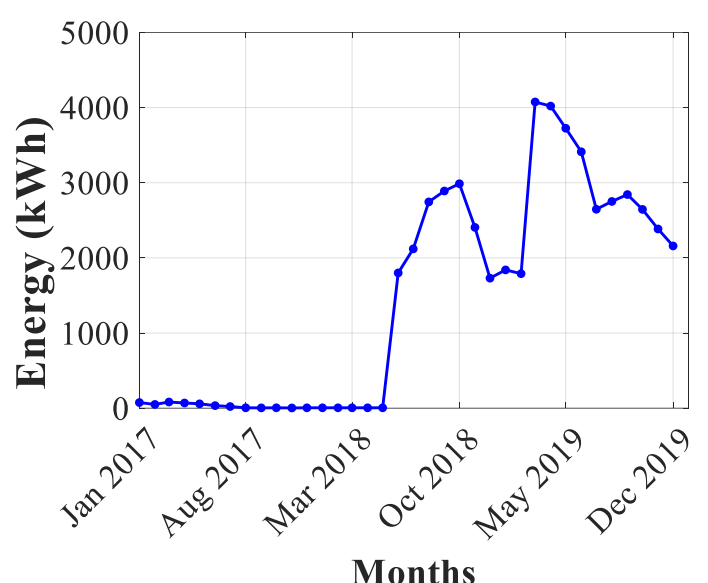

(a) Poultry farm consumer

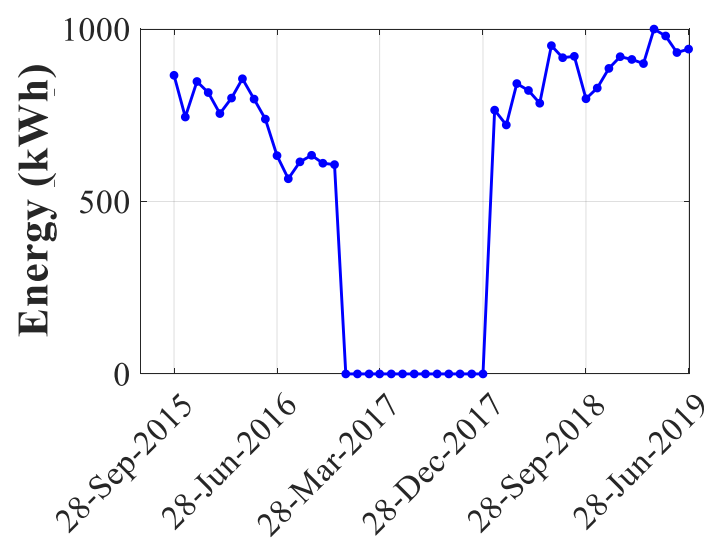

Months

(c) Bar-restaurant consumer

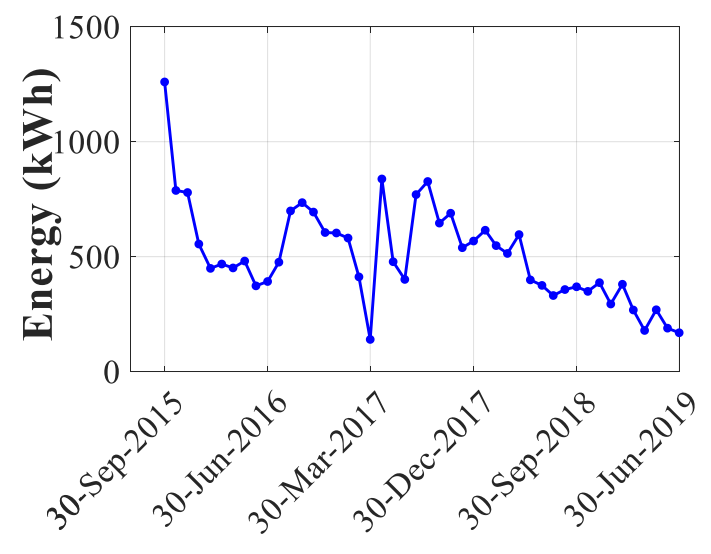

Months

(e) Commercial customer

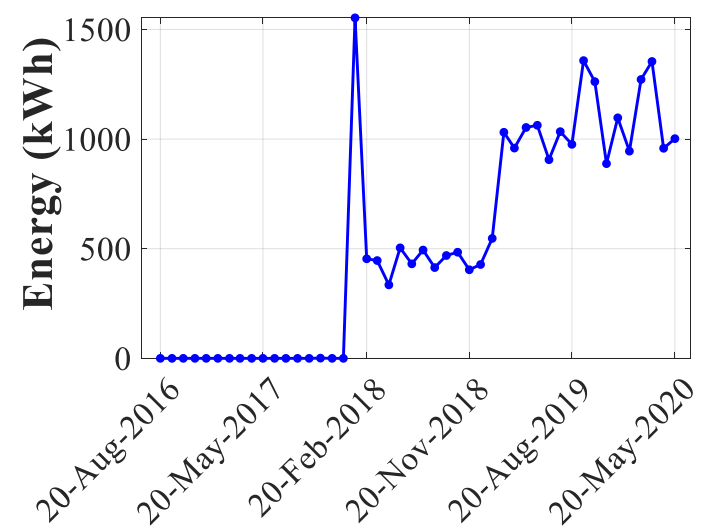

Months

(b) Consumer of cocoa processing plant

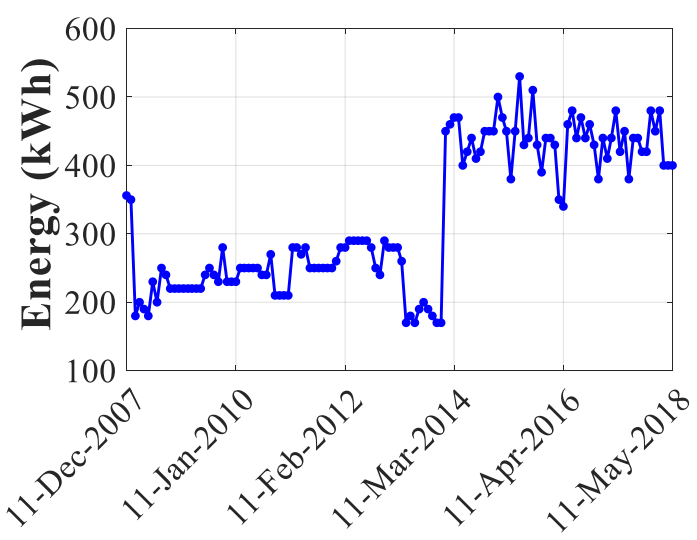

Months

(d) Demand curve for metal industry

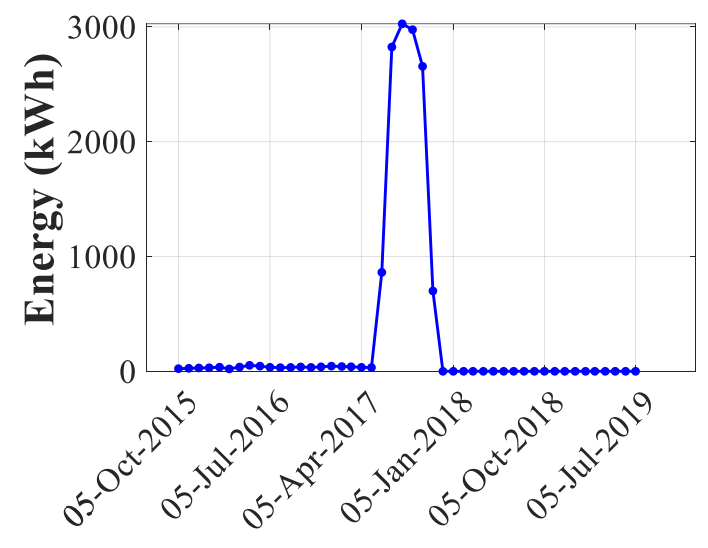

Months

(f) Residential customer

Figure 10. Errors in measurement. 


\section{Conclusions}

This research provides a data processing methodology that improves the detection and identification of fraud in electricity consumption by a comprehensive analysis of consumption patterns using data analytics techniques and artificial neural networks. Combining the k-means clustering and forecasting methods with neural networks gives the smallest error in the algorithm of $14 \%$ for the true positive data. The second method presents an error of $18 \%$; it uses the k-means grouping method with two groups $(k=2)$; the third method that best adjusts to the detection of true positives is the combination between the k-means algorithm and k-nearest neighbors with $40 \%$.

Data mining techniques, accompanied by algorithms with supervised and unsupervised methods and artificial intelligence models, have gained particular interest in the electricity sector since their application depends on the efficiency and effectiveness of the processes.

The computation time used to run the methodology was around $25 \mathrm{~min}$, with approximately 15,225 clients and 64 variables, to deliver 1816 reviews. This time can be decreased considerably with the use of supercomputers. On the other hand, it is important to stratify the planning of potential revisions by zones to keep the revision records updated.

The analysis window in this methodology is monthly; however, it can be narrower even in real time with advanced measurement infrastructure; the amount of data will grow exponentially, requiring the use of servers and big data.

The methodology uses $30 \%$ of the knowledge to forecast $70 \%$ of the unsupervised methods; the function of these algorithms is to determine patterns to acquire training according to the available variables for a label in the analysis. However, when the sample does not have sufficient data, numerous errors are generated in the forecast.

The methodology used to reduce NTLs is beneficial for the energy distribution sector. It can be extended to many utilities in LAC and the rest of the world that present similar situations; moreover, from the social point of view, a culture of efficient use of electricity can be developed.

Using the information from CIS, GIS, and socio-economic data, multivariate data analysis methods, classification, grouping algorithms (k-means), and neural networks can be applied to obtain a list of possible revisions of the measurement systems, to optimize the revisions and their routes, and to recover the most unbilled energy.

The projects that originate through this methodology will allow obtaining an economic return in the short term. The rapid change that technological advances promote daily allows various investigations such that more in-depth studies can be performed on distribution systems, especially for mitigating non-technical energy losses.

This research recommends investing in electrical projects that consider applying these techniques since financial indicators will always be positive and recovery will be obtained in the short term.

Author Contributions: Conceptualization, M.T.-O. and C.A.-M.; methodology, M.T.-O.; software, C.A.-M. and M.T.-O.; investigation M.T.-O., C.A.-M., C.Á.-B., and J.R.-G.; validation, C.Á.-B., D.M.J., J.R.-G., and E.B.-P.; formal analysis, M.T.-O. and C.Á.-B.; resources, M.T.-O. and C.A.-M.; data curation, M.T.-O., C.A.-M., J.R.-G., and E.B.-P.; writing—original draft preparation, M.T.-O.; writingreview, and editing, C.A.-M. and C.Á.-B.; supervision, C.Á.-B. and D.M.-J.; project administration, M.T.-O. All authors read and agreed to the published version of the manuscript.

Funding: This research received funding from the project Smart GrI+D+i from the Universidad Católica de Cuenca in Ecuador.

Data Availability Statement: Not applicable.

Acknowledgments: The authors thank the "CENTROSUR" utility for their valuable input with data and evidence for the success of this research.

Conflicts of Interest: The authors declare no conflict of interest. 


\begin{tabular}{|c|c|}
\hline \multicolumn{2}{|c|}{ Abbreviations } \\
\hline \multicolumn{2}{|c|}{ The following abbreviations are used in this manuscript: } \\
\hline NTL & Non-technical losses \\
\hline GIS & Geographic information system \\
\hline CIS & Customer information systems \\
\hline SAP & System application products \\
\hline CENTROSUR & Empresa Eléctrica Regional Centro Sur C.A. \\
\hline TPR & True positive rate \\
\hline FPR & False positive rate \\
\hline $\mathrm{TP}$ & True positives \\
\hline $\mathrm{TN}$ & True negatives \\
\hline FP & False positives \\
\hline FN & False negatives \\
\hline $\mathrm{k}-\mathrm{NN}$ & k-nearest neighbor \\
\hline ANN & Artificial neural network \\
\hline SVM & Support vector machine \\
\hline OPF & Optimum path forest \\
\hline AUC & Area under the curve \\
\hline
\end{tabular}

\section{References}

1. Organización Latinoamericana de Energía-OLADE. Panorama Energético de Latinoamérica y el Caribe; OLADE:Quito, Ecuador, 2019; Volume I.

2. Alvarez, C.M.; Rodriguez, J.; Alcazar, M.; Carbonell, J. Análisis para la Implementación de Redes Inteligentes en Ecuador; Editorial Institucional UPV: Valencia, Spain, 2016; Volume I, pp. 1-287, ISBN 978-84-608-5432-6.

3. Costa, B.; Alberto, B.; Portela, A.; Maduro, M.; Eler, E. Fraud Detection in Electric Power Distribution Networks using an Ann-Based Knowledge-Discovery Process. Int. J. Artif. Intell. Appl. 2013, 4, 17-23. [CrossRef]

4. Leon, C.; Biscarri, F.; Monedero, I.; Guerrero, J.I.; Biscarri, J.; Millan, R. Variability and Trend-Based Generalized Rule Induction Model to NTL Detection in Power Companies. IEEE Trans. Power Syst. 2011, 26, 1798-1807. [CrossRef]

5. Monedero, I.; Biscarri, F.; León, C.; Guerrero, J.; Biscarri, J.; Millán, R. Detection of frauds and other non-technical losses in a power utility using Pearson coefficient, Bayesian networks and decision trees. Int. J. Electr. Power Energy Syst. 2011, 34, 90-98. [CrossRef]

6. Nizar, A.H.; Dong, Z.Y.; Zhao, J.H.; Zhang, P. A Data Mining Based NTL Analysis Method. In Proceedings of the 2007 IEEE Power Engineering Society General Meeting, Tampa, FL, USA, 24-28 June 2007; pp. 1-8. [CrossRef]

7. Leite, D.; Pessanha, J.; Simões, P.; Calili, R.; Souza, R. A Stochastic Frontier Model for Definition of Non-Technical Loss Targets. Energies 2020, 13, 3227. [CrossRef]

8. Arthur, D.; Vassilvitskii, S. K-Means++: The Advantages of Careful Seeding. In Proceedings of the Eighteenth Annual ACM-SIAM Symposium on Discrete Algorithms, New Orleans, LA, USA, 7-9 January 2007; pp. 1027-1035.

9. Sun, S.; Huang, R. An adaptive k-nearest neighbor algorithm. In Proceedings of the 2010 Seventh International Conference on Fuzzy Systems and Knowledge Discovery, Yantai, China, 10-12 August 2010; Volume 1, pp. 91-94. [CrossRef]

10. Ramos, C.C.O.; de Sousa, A.N.; Papa, J.P.; Falcão, A.X. A New Approach for Nontechnical Losses Detection Based on OptimumPath Forest. IEEE Trans. Power Syst. 2011, 26, 181-189. [CrossRef]

11. Nagi, J.; Yap, K.S.; Tiong, S.K.; Ahmed, S.K.; Nagi, F. Improving SVM-Based Nontechnical Loss Detection in Power Utility Using the Fuzzy Inference System. IEEE Trans. Power Deliv. 2011, 26, 1284-1285. [CrossRef]

12. León, C.; Biscarri, F.; Monedero, I.; Guerrero, J.; Biscarri, J.; Millán, R. Integrated Expert System Applied to the Analysis of Non Technical Losses In Power Utilities. Expert Syst. Appl. 2011, 38, 10274-10285. [CrossRef]

13. Toledo, M.; Morales, D.; Vintimilla, J.; Medina, R. Smart multivariate techniques applied in the budget assignment for loss reduction in ecuador. In Proceedings of the 2016 IEEE PES Innovative Smart Grid Technologies Conference Europe (ISGT-Europe), Ljubljana, Slovenia, 9-12 October 2016; Volume I, pp. 1-6. [CrossRef]

14. Ministerio de Energía y Recursos Naturales no Renovables. Plan Maestro de Electricidad of_Ecuador; Ministry of Electricity and Renewable Energy: Quito, Ecuador, 2018; Volume I, pp. 1-390.

15. Zhang, T.; Gao, R.; Sun, S. Theories, Applications and Trends of Non-Technical Losses in Power Utilities Using Machine Learning. In Proceedings of the 2018 2nd IEEE Advanced Information Management, Communicates, Electronic and Automation Control Conference (IMCEC), Xi'an, China, 25-27 May 2018; pp. 2324-2329. [CrossRef]

16. Pózna, A.; Fodor, A.; Hangos, K. Model-based fault detection and isolation of non-technical losses in electrical networks. Math. Comput. Model. Dyn. Syst. 2019, 25, 397-428. [CrossRef]

17. Jamil, F.; Ahmad, E. Policy considerations for limiting electricity theft in the developing countries. Energy Policy 2019, 129, 452-458. [CrossRef] 
18. CIRED. Reduction of Technical and Non-Technical Losses in Distribution Networks. In Proceedings of the International Conference on Electricity Distribution, Lyon, France, 15-18 June 2015.

19. Romero Agüero, J. Improving the efficiency of power distribution systems through technical and non-technical losses reduction. In Proceedings of the PES T \& D 2012, Orlando, FL, USA, 7-10 May 2012; pp. 1-8. [CrossRef]

20. Viegas, J.L.; Esteves, P.R.; Melício, R.; Mendes, V.M.F.; Vieira, S.M. Solutions for detection of non-technical losses in the electricity grid: A review. Renew. Sustain. Energy Rev. 2017, 80, 1256-1268. [CrossRef]

21. Monteiro, M.D.; Maciel, R.S. Detection of commercial losses in electric power distribution systems using data mining techniques. In Proceedings of the 2018 Simposio Brasileiro de Sistemas Eletricos (SBSE), Niteroi, Brazil, 12-16 May 2018; pp. 1-6. [CrossRef]

22. Messinis, G.; Hatziargyriou, N. Review of non-technical loss detection methods. Electr. Power Syst. Res. 2018, 158, 250-266. [CrossRef]

23. Ahmad, T.; Chen, H.; Wang, J.; Guo, Y. Review of various modeling techniques for the detection of electricity theft in smart grid environment. Renew. Sustain. Energy Rev. 2018, 82. [CrossRef]

24. Gonzalez-Urdaneta, G. A venezuelan experience in the reduction of non-technical power losses. In Proceedings of the CICED 2010 Proceedings, Nanjing, China, 13-16 September 2010; pp. 1-6.

25. Yakubu, O.; Babu, C.N.; Adjei, O. Electricity theft: Analysis of the underlying contributory factors in Ghana. Energy Policy 2018, 123, 611-618. [CrossRef]

26. Glauner, P.; Glaeser, C.; Dahringer, N.; Valtchev, P.; State, R.; Duarte, D. Non-Technical Losses in the 21st Century: Causes, Economic Effects, Detection and Perspectives; Interdisciplinary Centre for Security, Reliability and Trust, University of Luxembourg: Luxembourg, 2018.

27. Aydin, Z.; Gungor, V.C. A Novel Feature Design and Stacking Approach for Non-Technical Electricity Loss Detection. In Proceedings of the 2018 IEEE Innovative Smart Grid Technologies (ISGT), Singapore, 22-25 May 2018; pp. 867-872. [CrossRef]

28. Ghori, K.M.; Rabeeh Ayaz, A.; Awais, M.; Imran, M.; Ullah, A.; Szathmary, L. Impact of Feature Selection on Non-technical Loss Detection. In Proceedings of the 2020 6th Conference on Data Science and Machine Learning Applications (CDMA), Riyadh, Saudi Arabia, 21-22 March 2020; pp. 19-24. [CrossRef]

29. Kosut, J.P.; Santomauro, F.; Jorysz, A.; Fernández, A.; Lecumberry, F.; Rodríguez, F. Abnormal consumption analysis for fraud detection: UTE-UDELAR joint efforts. In Proceedings of the 2015 IEEE PES Innovative Smart Grid Technologies Latin America (ISGT LATAM), Montevideo, Uruguay, 5-7 October 2015; pp. 887-892. [CrossRef]

30. wang, D.-G.; Dong, J.-C.; Huang, L.; Gong, Y. Anomaly Behavior Detection Based on Ensemble Decision Tree in Power Distribution Network. In Proceedings of the 2018 4th Annual International Conference on Network and Information Systems for Computers (ICNISC), Wuhan, China, 19-21 April 2018; pp. 312-316. [CrossRef]

31. Guerrero, J.I.; Monedero, I.; Biscarri, F.; Biscarri, J.; Millán, R.; León, C. Non-Technical Losses Reduction by Improving the Inspections Accuracy in a Power Utility. IEEE Trans. Power Syst. 2018, 33, 1209-1218. [CrossRef]

32. Yap, K.S.; Tiong, S.K.; Nagi, J.; Koh, J.S.; Nagi, F. Comparison of supervised learning techniques for non-technical loss detection in power utility. Int. Rev. Comput. Softw. 2012, 7, 626-636.

33. Guerrero, J.; León, C.; Monedero, I.; Biscarri, F.; Biscarri, J. Improving Knowledge-Based Systems with statistical techniques, text mining, and neural networks for non-technical loss detection. Knowl.-Based Syst. 2014, 71, 376-388. [CrossRef]

34. Ford, V.; Siraj, A.; Eberle, W. Smart grid energy fraud detection using artificial neural networks. In Proceedings of the 2014 IEEE Symposium on Computational Intelligence Applications in Smart Grid (CIASG), Orlando, FL, USA, 9-12 December 2014; pp. 1-6. [CrossRef]

35. Micheli, G.; Soda, E.; Vespucci, M.; Gobbi, M.; Bertani, A. Big data analytics: an aid to detection of non-technical losses in power utilities. Comput. Manag. Sci. 2018, 16, 1-15. [CrossRef]

36. Barros, R.; Costa, E.; Araujo, J. Use of ANN for identification of consumers with irregular electrical installations. In Proceedings of the 2018 Simposio Brasileiro de Sistemas Eletricos (SBSE), Niteroi, Brazil, 12-16 May 2018; pp. 1-6. [CrossRef]

37. Ramos, C.; Rodrigues, D.; Souza, A.; Papa, J. On the Study of Commercial Losses in Brazil: A Binary Black Hole Algorithm for Theft Characterization. IEEE Trans. Smart Grid 2016, 9, 1-1. [CrossRef]

38. Messinis, G.M.; Hatziargyriou, N.D. Unsupervised Classification for Non-Technical Loss Detection. In Proceedings of the 2018 Power Systems Computation Conference (PSCC), Dublin, Ireland, 11-15 June 2018; pp. 1-7. [CrossRef]

39. Umar, H.A.; Prasad, R.; Fonkam, M. Assessing Severity of Non-technical Losses in Power using Clustering Algorithms. In Proceedings of the 2019 15th International Conference on Electronics, Computer and Computation (ICECCO), Abuja, Nigeria, 10-12 December 2019; pp. 1-6. [CrossRef]

40. Terciyanli, E.; Eryigit, E.; Emre, T.; Caliskan, S. Score based non-technical loss detection algorithm for electricity distribution networks. In Proceedings of the 2017 5th International Istanbul Smart Grid and Cities Congress and Fair (ICSG), Istanbul, Turkey, 19-21 April 2017; pp. 180-184. [CrossRef]

41. Babu, T.V.; Murthy, T.S.; Sivaiah, B. Detecting unusual customer consumption profiles in power distribution systems - APSPDCL. In Proceedings of the 2013 IEEE International Conference on Computational Intelligence and Computing Research, Enathi, India, 26-28 December 2013; pp. 1-5. [CrossRef]

42. Yeckle, J.; Tang, B. Detection of Electricity Theft in Customer Consumption Using Outlier Detection Algorithms. In Proceedings of the 2018 1st International Conference on Data Intelligence and Security (ICDIS), South Padre Island, TX, USA, 8-10 April 2018; pp. 135-140. [CrossRef] 
43. Moghaddass, R.; Wang, J. A Hierarchical Framework for Smart Grid Anomaly Detection Using Large-Scale Smart Meter Data. IEEE Trans. Smart Grid 2018, 9, 5820-5830. [CrossRef]

44. Zanetti, M.; Jamhour, E.; Pellenz, M.; Penna, M.; Zambenedetti, V.; Chueiri, I. A Tunable Fraud Detection System for Advanced Metering Infrastructure Using Short-Lived Patterns. IEEE Trans. Smart Grid 2019, 10, 830-840. [CrossRef]

45. Kazymov, I.; Kompaneets, B. Definition of Fact and Place of Losses in Low Voltage Electric Networks. In Proceedings of the 2019 International Conference on Industrial Engineering, Applications and Manufacturing (ICIEAM), Sochi, Russia, 25-29 March 2019; pp. 1-5. [CrossRef]

46. Jindal, A.; Dua, A.; Kaur, K.; Singh, M.; Kumar, N.; Mishra, S. Decision Tree and SVM-Based Data Analytics for Theft Detection in Smart Grid. IEEE Trans. Ind. Inform. 2016, 12, 1005-1016. [CrossRef]

47. Pulz, J.; Muller, R.B.; Romero, F.; Meffe, A.; Neto, A.F.G.; Jesus, A.S. Fraud detection in low-voltage electricity consumers using socio-economic indicators and billing profile in smart grids. CIRED-Open Access Proc. J. 2017, 2017, 2300-2303. [CrossRef]

48. Messinis, G.M.; Rigas, A.E.; Hatziargyriou, N.D. A Hybrid Method for Non-Technical Loss Detection in Smart Distribution Grids. IEEE Trans. Smart Grid 2019, 10, 6080-6091. [CrossRef]

49. Zheng, K.; Chen, Q.; Wang, Y.; Kang, C.; Xia, Q. A Novel Combined Data-Driven Approach for Electricity Theft Detection. IEEE Trans. Ind. Inform. 2019, 15, 1809-1819. [CrossRef]

50. Bholowalia, P.; Kumar, A. EBK-Means: A Clustering Technique based on Elbow Method and K-Means in WSN. Int. J. Comput. Appl. 2014, 105, 17-24.

51. Passos Júnior, L.; Ramos, C.; Rodrigues, D.; Pereira, D.; Souza, A.; Costa, K.; Papa, J. Unsupervised non-technical losses identification through optimum-path forest. Electr. Power Syst. Res. 2016, 140. [CrossRef]

52. Al-Radaideh, Q.A.; Al-Zoubi, M.M. A data mining based model for detection of fraudulent behaviour in water consumption. In Proceedings of the 2018 9th International Conference on Information and Communication Systems (ICICS), Irbid, Jordan, 3-5 April 2018; pp. 48-54. [CrossRef]

53. Glauner, P.; Meira, J.A.; Dolberg, L.; State, R.; Bettinger, F.; Rangoni, Y. Neighborhood Features Help Detecting Non-Technical Losses in Big Data Sets. In Proceedings of the 2016 IEEE/ACM 3rd International Conference on Big Data Computing Applications and Technologies (BDCAT), Shanghai, China, 6-9 December 2016; pp. 253-261.

54. Rokach, L.; Maimon, O. Data Mining with Decision Trees: Theory and Applications; Series in Machine Perception and Artificial Intelligence; World Scientific: Singapore, 2015.

55. Glauner, P.; Meira, J.; Valtchev, P.; State, R.; Bettinger, F. The Challenge of Non-Technical Loss Detection Using Artificial Intelligence: A Survey. Int. J. Comput. Intell. Syst. 2017, 10, 760-775. [CrossRef] 